\section{Comment}

Most pathological manifestations of thalassaemia major are attributed to haemosiderosis owing to transfusions. Iron deposits in the heart, liver, pancreas, and endocrine glands have been described. ${ }^{2}$ In this patient with the sicca syndrome we found heavy deposition of iron in the labial salivary glands similar to that described in a woman with idiopathic haemochromatosis. ${ }^{1}$ We were unable to distinguish the syndrome from Sjögren's syndrome on clinical grounds. Sjögren's syndrome is an autoimmune disorder affecting mainly postmenopausal women. It is the result of lymphocyte mediated destruction of the exocrine glands and can occur alone or in association with another connective tissue disorder, most commonly rheumatoid arthritis. Our patient never had symptoms of connective tissue disease or enlargement of the parotid gland. His HLA type was not the one (B8 and DR3 or 4) usually associated with Sjögren's syndrome. Thyroid autoantibodies were not present. He did have hypergammaglobulinaemia and was positive for rheumatoid factor and antinuclear antibodies. High concentrations of gammaglobulin, however, are almost invariably present in patients with thalassaemia, ${ }^{3}$ and rheumatoid factor and antinuclear antibodies have been found in $31 \%$ and $13 \%$ respectively of a series of unselected patients with $\beta$ thalassaemia major ${ }^{4}$ and have been attributed to the repeated antigenic stimuli received with transfusions. The histological appearance of the salivary glands, with heavy deposition of iron in glandular acini and absence of lymphocytic infiltration, did not support a diagnosis of Sjögren's syndrome but suggested damage related to iron.

Although we could not with certainty rule out associated autoimmune disease, we are inclined to regard the sicca syndrome in our patient as a consequence of iron overload. Disease of the exocrine portion of the pancreas leading to reduced serum chymotrypsin concentrations has been described in patients with thalassaemia and has been attributed to infiltration of the acinar tissue by iron. ${ }^{5}$ With the improvement in life expectancy due to intensive transfusion regimens and aggressive chelation of iron, doctors taking care of patients with thalassaemias are likely to see new symptoms developing in this previously non-existent population of adult patients. The sicca syndrome may be one of them.

Professor G Veneroni, Centro Trasfusionale, Ospedale Fatebenefratelli, performed the HLA typing.

\section{References}

1 Blandford RL, Dowdle JR, Stephens MR, Walker DM. Sicca syndrome associated with idiopathic haemochromatosis. $\mathrm{Br}$ Med $\mathcal{F} 1979 ; \mathrm{i}: 1323$.

2 O'Brien RT. Iron overload: clinical and pathologic aspects in pediatrics. Semin Hematol 1977;15:115-25.

3 Tovo PA, Miniero R, Barbera C, Sacchetti L, Saitta M. Serum immunoglobulins in homozygous beta-thalassemia. Acta Haematol (Basel) $1981 ; 65: 21-5$.

4 Economidou J, Pathouli C, Hadziyannis S, Fostiropoulos G, Constantoulakis M. Complement levels in relation to certain antibodies in polytransfused thalassaemic patients. Vox Sang 1976;31, suppl 1: 32-8.

${ }^{5}$ Hussain MAM, Dandona P, Fedail SS, Ramdial L, Flynn D, Hoffbrand AV. Serum immunoreactive trypsin in beta-thalassaemia major. $\mathrm{f} \mathrm{Clin}$ Pathol $1981 ; 45: 970-1$.

(Accepted 24 November 1983)

\title{
Glycosylation of hair: possible measure of chronic hyperglycaemia
}

\author{
R B PAISEY, J R CLAMP, M J C KENT, N D LIGHT, M HOPTON, M HARTOG
}

\begin{abstract}
To determine whether hair is excessively glycosylated in diabetes mellitus $4 \mathrm{~cm}$ hair samples were taken proximally from behind the ear in 50 white non-diabetics and 46 diabetics. Hair glycosylation was assayed by a modification of the thiobarbituric acid reaction. Blood was taken from the diabetics at the same time for measurement of glycosylated haemoglobin concentration.

The mean (1 SD) concentration of fructosamine ( $\mu \mathrm{mol} / 100 \mathrm{mg}$ hair) was 0.054 (0.011) for normal hair. Glycosylation was not related to sex, age, or hair colour. The diabetics' hair was more heavily glycosylated $(0.097(0.045))$ than normal $(p<0.01)$ and there was a
\end{abstract}

University Department of Medicine, Bristol Royal Infirmary, Bristol BS2 8HW

R B PAISEY, MRCP, lecturer in medicine

J R CLAMP, MD, professor of experimental medicine

M HOPTON, research technician

M HARTOG, FRCP, reader in medicine

ARC Meat Research Institute, Langford, Nr Bristol, Avon BS18 7DY M J C KENT, DPHIL, research associate

N D LIGHT, PHD, head of collagen section

Correspondence to: Dr R B Paisey. correlation between hair glycosylation and the concentration of glycosylated haemoglobin in the diabetics $(\mathbf{r}=0.71 ; p<0.01)$. Hair from non-diabetics showed a stable time related increase in glycosylation when incubated with glucose.

Glycosylation of hair might provide a stable long term measure of tissue glycosylation, useful in the investigation of microvascular complications of diabetes mellitus.

\section{Introduction}

The discovery of increased non-enzymatically glycosylated haemoglobin concentrations in diabetes mellitus ${ }^{1-4}$ has led to intensive research into similar excess glycosylation of other tissue proteins, especially in an attempt to establish a link between this process and chronic complications of the condition. Measurement of the percentage concentration of glycosylated haemoglobin has proved useful in assessing diabetic control, but tissue collagen, which is susceptible to functional changes from excessive glycosylation, has a much slower rate of turnover than haemoglobin. ${ }^{5}$ It is therefore of interest to investigate possible longer term markers of hyperglycaemia than haemoglobin, and we have conducted such a study.

As it is not feasible repeatedly to sample tissues containing basement membrane from the same subject, we investigated the 
hypothesis that free amino groups in hair keratin might be glycosylated and provide a stable measure of long term diabetic control. During the anagen phase scalp hair is secreted at approximately $0.37 \mathrm{~mm} /$ day. $^{6}{ }^{7}$ In this study we measured glycosylation of the proximal $4 \mathrm{~cm}$ of scalp hair in normal and diabetic subjects.

\section{Subjects and methods}

Fifty non-diabetic white subjects (age range 15-60 years; 29 women) served as controls. All were fit medical, nursing, or technical members of the staff of the Bristol Royal Infirmary. Natural hair colours in the group were red, blonde, brown, and black. The patients comprised 27 insulin dependent diabetics (age range 17-58 years; 13 women) and 19 non-insulin-dependent diabetics (age range 40-65 years; 9 women). None had a significant proportion of grey hairs in the samples taken from behind the ear. The diabetics were chosen from one diabetic outpatient clinic at the Bristol Royal Infirmary. All were regular clinic attenders who had blood taken for measurement of glycosylated haemoglobin concentration at the time of hair sampling.

TABLE I-Glycosylation of samples of scalp hair* from normal and diabetic subjects

\begin{tabular}{|c|c|c|c|}
\hline & No & Sample & $\begin{array}{c}\text { Mean glycosylation } \\
\text { of hair } \\
\text { ( } \mu \mathrm{mol} \text { fructosamine/ } \\
100 \mathrm{mg} \text { hair })(1 \mathrm{SD})\end{array}$ \\
\hline Normal subjects & $\begin{array}{r}50 \\
6\end{array}$ & $\left\{\begin{array}{l}\text { Proximal } 4 \mathrm{~cm} \\
\text { Proximal } 5 \mathrm{~cm} \\
\text { Middle } 5 \mathrm{~cm} \\
\text { Distal } 5 \mathrm{~cm}\end{array}\right.$ & $\begin{array}{l}0.054(0.011) \\
0.058(0.008) \\
0.059(0.012) \\
0.058(0.010)\end{array}$ \\
\hline $\begin{array}{l}\text { Insulin-dependent diabetics } \\
\text { Non-insulin-dependent diabetics }\end{array}$ & $\begin{array}{l}27 \\
19\end{array}$ & $\begin{array}{l}\text { Proximal } 4 \mathrm{~cm} \\
\text { Proximal } 4 \mathrm{~cm}\end{array}$ & $\begin{array}{l}0.096(0.047)+ \\
0.099(0.041) \dagger\end{array}$ \\
\hline
\end{tabular}

* All taken from behind the ear.

+Significantly greater than normal $(p<0.01$; unpaired $t$ test with allowance for

Conversion: $S I$ to traditional units-Fructosamine: $1 \mu \mathrm{mol} \approx 180 \mu \mathrm{g}$
Hexosyl lysine estimations-Hair samples were powdered with a freezer mill, reduced with tritiated sodium borohydride, and subjected to amino acid analysis on columns after acid hydrolysis. Hexosyl lysine was measured as the percentage of total radioactivity in disintegrations per minute found in the fraction corresponding to lysine. ${ }^{10}$

Gas-liquid chromatography-Hair samples $(10 \mathrm{mg}$ ) were incubated in methanol-hydrochloric acid before standard analysis for hexoses with arabinitol and mannitol standards. ${ }^{11}$

Statistics-Results were evaluated using least mean squares regression analysis for correlations, with analysis of variance and paired and unpaired $t$ tests for differences between groups; for the difference between glycosylation of normal and diabetic hair an unpaired $t$ test allowing for dissimilar variances was used.

\section{Results}

Table I shows the ranges of glycosylation of hair from the normal and diabetic subjects. Glycosylation was unchanged along the whole length of the hair in six normal subjects. There was no alteration in the normal range of hair glycosylation with age, sex, or colour or texture of the hair among the non-diabetic population studied.

The mean degree of glycosylation of hair from the diabetic subjects was significantly greater than normal $(p<0.01)$ (table I) in both the insulin dependent and non-insulin-dependent groups. Hair from both groups of diabetics was glycosylated in proportion to the glycosylated haemoglobin values $(p<0.01)$ (see figure), although the results showed considerable scatter.

Table II gives the results of incubating hair from non-diabetics in glucose solutions of 10,20 , and $50 \mathrm{mmol} / \mathrm{l}$. A significant increase in glycosylation occurred, which remained stable despite repeated washing or prolonged incubation in distilled water.

Reduction of powdered hair samples with tritiated borohydride yielded more hexosyl lysine in hair from normal subjects incubated with glucose and in hair from diabetics than in the original, nonincubated samples.

Gas-liquid chromatographic sugar analysis of methanol-hydrochloric acid extracted hair showed only insignificant quantities of free hexoses to be present.

TABLE II-Fructosamine concentrations ( $\mu$ mol/100 mg hair) after incubation of hair from normal subjects in glucose. (Values are means (1 SD in parentheses) of four samples or means of duplicate samples when no SD quoted)

\begin{tabular}{|c|c|c|c|c|c|c|}
\hline \multirow{2}{*}{\multicolumn{2}{|c|}{ Incubation medium }} & \multicolumn{5}{|c|}{ Days of incubation } \\
\hline & & 2 & 10 & 15 & 25 & 40 \\
\hline $\begin{array}{l}\text { Distilled } \\
\text { Glucose }\end{array}$ & $\left\{\begin{array}{l}10 \mathrm{mmol} / 1(180 \mathrm{mg} / 100 \mathrm{ml}) \\
20 \mathrm{mmol} / 1(360 \mathrm{mg} / 100 \mathrm{ml}) \\
50 \mathrm{mmol} / 1(900 \mathrm{mg} / 100 \mathrm{ml})\end{array}\right.$ & $\begin{array}{l}0.054(0.006) \\
0.060(0.006)\end{array}$ & $\begin{array}{l}0.051 \\
0.075 \\
0.148(0.007)^{*} \\
0.364(0.008)^{*}\end{array}$ & $\begin{array}{l}0.087(0.003)^{*} \\
0.210(0.007)^{*}\end{array}$ & $\begin{array}{l}0.135(0.005)^{*} \\
0.241(0.008)^{*}\end{array}$ & $\begin{array}{l}0.052 \\
0.155\end{array}$ \\
\hline
\end{tabular}

* Significantly higher than original control value $(\mathrm{p}<0 \cdot 01$; paired $t$ test $)$
Conversion: $S I$ to traditional units-Fructosamine: $1 \mu \mathrm{mol} \approx 180 \mu \mathrm{g}$.

Glycosylated haemoglobin was assayed by agar gel electrophoresis ${ }^{8}$ on samples of blood anticoagulated by edetic acid and previously incubated overnight in glucose free saline at $23^{\circ} \mathrm{C}$.

Glycosylation of hair-Hair taken from behind the ear was cut up finely and $100 \mathrm{mg}$ samples incubated for two hours at $120^{\circ} \mathrm{C}$ in an autoclave with $2 \mathrm{ml}$ oxalic acid $(1 \mathrm{~mol} / \mathrm{l}) .{ }^{9}$ When cool $1 \mathrm{ml} 20 \%$ trichloroacetic acid was added to each tube, the tubes centrifuged, and two $1 \mathrm{ml}$ aliquots of the supernatant taken. One aliquot was incubated with $0.25 \mathrm{ml}$ saturated thiobarbituric acid solution, and the other with $0.25 \mathrm{ml}$ distilled water for 50 minutes at $40^{\circ} \mathrm{C}$. The colour produced was measured by spectrophotometry at $443 \mathrm{~nm}$, the distilled water incubate serving as a sample blank. The interassay coefficient of variation was $3.9 \%$ for normal and $8.5 \%$ for diabetic samples. Serial dilutions of $1 \mathrm{mmol}$ fructose per $1(180 \mathrm{mg} / 100 \mathrm{ml})$ were used as a standard curve in each assay; equivalent dilutions of other hexoses, including glucose, galactose, sialic acid, mannose, and arabinose, generated less than $10 \%$ of the colour produced by fructose.

Incubation experiments-Finely cut hair was incubated in glucose solutions of 10,20 , and $50 \mathrm{mmol} / 1(180,360$, and $900 \mathrm{mg} / 100 \mathrm{ml})$ with a crystal of azide in each tube. After incubation samples were washed in guanidinium hydrochloride and distilled water to remove free glucose; incubations in distilled water were used as controls.

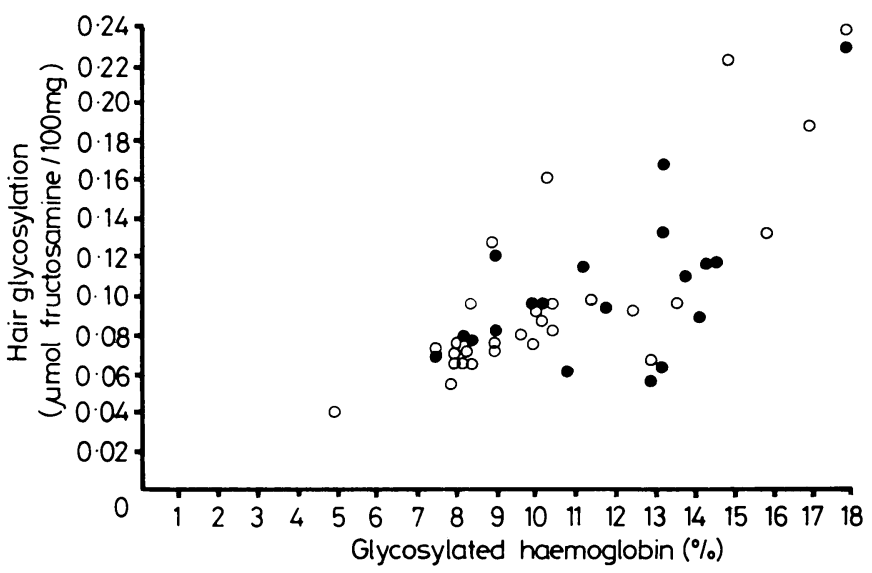

Relation between glycosylation of proximal $4 \mathrm{~cm}$ scalp hair and glycosylated haemoglobin value in insulin dependent $(O)$ and non-insulin dependent (O) diabetics $(n=46 ; r=0.71 ; y=-0.0145+0.0103 x)$.

Conversion: SI to traditional units-Fructosamine: $1 \mu \mathrm{mol} \approx 180 \mu \mathrm{g}$. 


\section{Discussion}

Our findings show that glycosylation of hair occurs and is increased in diabetes. Furthermore, glycosylation of hair from normal subjects may be increased by incubation with glucose solutions in proportion to the glucose concentration used. The results of reduction with tritiated borohydride and amino acid analysis and of gas-liquid chromatographic sugar analyses indicated that the glycosylation is at least partly accounted for by the presence of hexosyl lysine in hair and that there are only insignificant quantities of free hexoses present.

Although there were significant correlations between glycosylation of the proximal $4 \mathrm{~cm}$ of hair and the simultaneously measured glycosylated haemoglobin value, there was a considerable scatter in the results. This scatter may be due partly to variation in the rate of hair growth and the fact that the length of hair of $4 \mathrm{~cm}$ used in most of our experiments represents a period of roughly 16 weeks at an assumed average rate of hair growth of $0.37 \mathrm{~mm} /$ day. $^{7}$ In contrast, the closest correlations of glycosylated haemoglobin values have been with mean blood glucose concentrations in the preceding eight to 12 weeks. ${ }^{4}$ In addition, however, it seems likely that hair proteins are glycosylated in vivo with different dynamics from haemoglobin, an important factor when evaluating possible links between tissue glycosylation and diabetic microvascular complications.

The finding that hair glycosylation remains stable along the length of the hair from scalp to tip in normal subjects suggests that a sufficiently long hair sample may provide a long term record of degree of hyperglycaemia, though a prospective study will be necessary to establish this conclusively.

Further investigation into the chemical nature of glycosylation of hair is needed. In addition to epsilon amino groups of lysine residues in keratin, $\mathrm{N}$ terminal amino groups and perhaps even amino groups on melanin may be glycosylated. These would not all necessarily be accessible for hydrolysis in the thiobarbituric acid assay.

Although glycosylation of hair is likely predominantly to occur during secretion of the hair shaft in the follicle, glucose may become bound to the mature hair shaft from sweat, and any extraneous substances capable of producing furfurals in the assay might produce falsely high readings. This latter possibility is unlikely, as prolonged washing of hair samples did not affect the result.

Finally, if more work confirms these findings the tests may be of use forensically, because of the stability of fructosamine in the hair, and also in population studies, where large numbers of samples might be taken quickly as a non-invasive procedure and stored easily.

We thank the patients and control subjects for their cooperation, Miss Julia Ford and Mr Nick Bowyer for their help with the figure, and Mrs Zina Fear for preparing the manuscript.

\section{References}

1 Trivelli LA, Ranney HM, Hong Tiens L. Hemoglobin components in patients with diabetes mellitus. $N$ Engl f Med 1971 ;284:353-7.

${ }^{2}$ Koenig RJ, Peterson CH, Jones RL, Saudele C, Lehrman M, Cerami A. Correlation of glucose regulation and hemoglobin $A_{1 c}$ in diabetes mellitus. N Engl f Med 1976;295:417-20.

${ }^{3}$ Fluckiger R, Berger $\mathrm{W}$, Winterhalter $\mathrm{KH}$. Haemoglobin $\mathrm{A}_{1 \mathrm{c}}$, a reliable index of diabetic control. Diabetologia 1978;13:393.

${ }^{4}$ Bunn HF, Gabbay KH, Gallop PM. The glycosylation of $\mathrm{Hb}$; relevance to diabetes mellitus. Science 1978;200:21-7.

${ }^{5}$ Hall DA. Gerontology: collagen disease. Clin Endocrinol Metab 1981; $10: 23-55$.

${ }^{6}$ Barman JM, Astore J, Pecoraro V. The normal trichogram of the adult. f Invest Dermatol $1965 ; 44: 233-49$.

7 Munro DD. Hair growth measurement using intradermal sulphur 35 L-cystine. Arch Dermatol 1966;93:119-34.

${ }^{8}$ Menard L, Dempsey ME, Blankstein LA, Aleyassine H, Wacks M, Soeldner JS. Quantitative determination of glycosylated hemoglobin $A_{1}$ by agar gel electrophoresis. Clin Chem 1980;26:1598-602.

9 Parker KM, England JD, Da Costa J, Hess RL, Goldstein DE. Improved colorimetric assay for glycosylated hemoglobin. Clin Chem $1981 ; 27$ : 669-72.

${ }^{10}$ Bailey AJ. The non-enzymatic glycosylation of proteins. Horm Metab Res 1981;suppl 11:90-4.

${ }^{11}$ Clamp JR, Bhatti T, Chambers RE. The determination of carbohydrate in biological materials by gas liquid chromatography. Methods Biochem Anal 1971;19:229-344.

(Accepted 10 fanuary 1984)

\title{
Impairment of physical performance after treatment with beta blockers and alpha blockers
}

\author{
CALLE BENGTSSON
}

\begin{abstract}
An investigation was made into the effect of various types of beta blockers, an alpha blocker, a combined alpha and beta blocker, and a diuretic on physical performance in a normotensive man. Beta blockers, the alpha blocker, and the combined alpha and beta blocker significantly $(p<0.001)$ reduced physical performance.
\end{abstract}

Further studies are needed to confirm these findings in a larger series of subjects.

\footnotetext{
Medical Department II, Sahlgrenska Hospital, Gothenburg University, S-413 45 Gothenburg, Sweden

CALLE BENGTSSON, MD, associate professor of internal medicine
}

\section{Introduction}

Beta blockers have been in clinical use for more than 10 years and are often taken by young and physically active patients. As reduced cardiac output and heart rate are among the most important effects of these drugs ${ }^{1}$ a reduction in physical performance might be expected and has been observed. ${ }^{2}{ }^{3}$ This problem has been discussed previously, ${ }^{4}$ but few systematic studies of it have been made.

\section{Subject and method}

I investigated the effects of various types of beta blockers, an alpha blocker, and a combined alpha and beta blocker on my maximal physical performance. I was normotensive, had been a short-distance runner when younger, and was aged 40 when I performed the first trial in 1974. I had taken regular physical exercise in my spare time since adolescence. 